\title{
COMPARATIVE REVIEW OF ARTIFICIAL LIGHT SOURCES FOR SOLAR-THERMAL BIOMASS CONVERSION RESEARCH APPLICATIONS
}

\author{
ANALIZA PORÓWNAWCZA SZTUCZNYCH ŹRÓDEŁ ŚWIATŁA \\ DO BADAŃ SOLARNO-TERMICZNEJ KONWERSJI BIOMASY
}

\begin{abstract}
In recent years solar-thermal methods of waste biomass conversion are promptly gaining on attention. For researchers working in areas that suffer from lack of natural solar power, the choice of proper solar simulator for the study is crucial. Solar simulator consist of artificial light source enclosed in proper housing with optical and cooling system, powered by dedicated power supply. Solar simulators are not only granting independence from external conditions, yet provide possibility of research expand due to tuneable output power and emissive spectrum. Over the years, solar simulators were powered by different types of lamps. Throughout the history, the solar simulators were used mainly in photovoltaic and space research, crystal growth industry, and the material testing. For mentioned purposes, the total thermal output power of simulator was playing secondary role in comparison to urgent need of spectral match, irradiance distribution and beam uniformity with terrestrial or extra-terrestrial sunlight. For thermal applications, solar simulators are facing the challenge of providing high output power, described by high radiant heat flux and high heat flux density over the specified target area. In presented paper the comparison of xenon arc, metal halide lams and tungsten halogen for thermal applications has been presented with emphasis on available thermal power, spectral match with natural sunlight and operational issues. The course of decision taken during the selection of artificial light source for construction of laboratory-scale solar pyrolytic reactor is proposed.
\end{abstract}

Keywords: solar energy, biomass, pyrolysis, xenon, renewables

\section{Introduction}

In 2016 almost $80 \%$ of world's final energy consumption is still provided by fossil fuels utilization, continuously diminished by rising growth rate in modern renewables. Increase in renewable energy deployment continued in 2017, especially in power sector, thanks to: increasing access to finance, global concerns about energy security, human health and the environment, growing energy demand in young and developing economies, urgent need for emission-free electric energy and clean cooking facilities and dedicated policy initiatives and support for ambitious targets [1].

\footnotetext{
${ }^{1}$ Institute of Thermal Technology, Silesian University of Technology, ul. S. Konarskiego 22, 44-100 Gliwice, Poland, phone +48 3223714 60, +48 3223729 83, email: sebastian.werle@polsl.pl

*Corresponding author: szymon.sobek@polsl.pl
} 
Biomass thermal conversion methods provide wide range of renewable fuels from low-calorific biomass, yet requires significant amount of heat necessary to carry out the reaction: gasification, torrefaction or pyrolysis. Typical biomass combustion methods are perceived as carbon-neutral technology, due to neutral $\mathrm{CO}_{2}$ balance of the process [2]. Plants assimilates carbon from the atmosphere during the photosynthesis in form of $\mathrm{CO}_{2}$, which is later released during the combustion process. Basu in 2010 [3] extended carbon-neutral term for biomass technology, claiming that plants during the combustion release $\mathrm{CO}_{2}$ absorbed only recently, thus thermal biomass processing does not add any $\mathrm{CO}_{2}$ to Earth's inventory. On the other hand, when comparing speed of the $\mathrm{CO}_{2}$ assimilation during photosynthesis and plant growth processes with speed of combustion on top of cumulative carbon footprints connected with biomass transport and processing, above mentioned thesis seems to be arguable.

\section{Biomass thermal conversion methods}

The goal of biomass thermal conversion methods is to produce renewable fuels from low calorific, waste organic matter. The conversion can be proceeded in several ways, where the most popular are: gasification, pyrolysis and torrefaction. Gasification is the process of converting a solid fuel into a gas by treating the solid fuel in a generator with oxygen, air, or steam [3, 4]. The heating value of the gas after gasification, being the mixture of $\mathrm{CO}, \mathrm{H}_{2}$, and lower hydrocarbons, varies around a value of $4 \mathrm{MJ} \cdot \mathrm{m}^{-3}[5]$. Pyrolysis can be defined as the thermal degradation of carbonaceous materials in oxygen-free atmosphere [6-9]. During pyrolysis always three products are produced: pyrolytic oil, gas and char. Numerous pyrolysis studies proved that pyrolysis process parameters, like temperature and heating rate, dictate the final product yields [10]. Generally the lower the energy supply, the higher the solid fraction yield with the lowest decomposition rates. The higher the temperatures and especially heating rates, first the more liquid and eventually gaseous fraction yields are denoted [10]. Torrefaction is low-temperature pyrolysis, which aims for biomass pre-treatment (upgrade) [11]. Low temperatures and heating rates prevents feedstock from intense decomposition in order to achieve dry, stable, more homogenous and hydrophobic solid torrefied fuel. The main clue why torrefaction is separated from pyrolysis is the process destination and ideology. While pyrolysis goal is to release the most of energy from biomass, the aim of torrefaction is to keep, upgrade and expose its energetic potential. Solar application of mentioned processes opens up the possibilities of storing solar energy in the form of usable chemical energy of post-process products, with no greenhouse gasses (GHG) emissions, due to emission-free nature of the concentrated solar power (CSP) and significantly lowers the heat acquisition cost.

\section{Solar radiation spectrum}

\section{Blackbody radiation}

During the discussion of thermal radiation, the concept of blackbody is very convenient. The blackbody is an theoretical, idealised object, with perfect absorption and emission of radiation, regardless of wavelength and radiation incident angle [12]. The sun can be considered as a blackbody radiator at a temperature of $5777 \mathrm{~K}$, which can be approximated to $5800 \mathrm{~K}$ [13]. In 1900, Max Planck found an elegant equation (eq. (1)) 
interpolating Wien approximation and Rayleigh-Jeans law, presenting the blackbody radiance as a function of wavelength $\lambda$ and temperature $T$ [12]:

$$
L_{e \lambda}(\lambda, T)=\frac{2 \mathrm{~h} v^{3}}{c^{2}}\left[\exp \left(\frac{\mathrm{h} v}{\lambda \mathrm{k}_{\mathrm{B}} T}\right)-1\right]^{-1}
$$

where: $L_{e \lambda}$ - radiance $\left[\mathrm{W} \cdot \mathrm{m}^{-2} \cdot \mathrm{sr}^{-1}\right], \lambda$ - wavelength $[\mathrm{m}], T$ - temperature $[\mathrm{K}], \mathrm{h}$ - the Planck constant $\left(\mathrm{h}=6.626 \cdot 10^{-34} \mathrm{~J} \cdot \mathrm{s}\right), c$ - speed of light in vacuum $\left(c=2.998 \cdot 10^{8} \mathrm{~m} \cdot \mathrm{s}^{-1}\right)$, $v$ - wave's frequency, $\left[\mathrm{s}^{-1}\right], \mathrm{k}_{\mathrm{B}}$ - the Boltzmann constant $\left(\mathrm{k}_{\mathrm{B}}=1.381 \cdot 10^{-23} \mathrm{~J} \cdot \mathrm{K}^{-1}\right)$.

\section{Solar radiation spectrum}

Solar radiation emissive spectrum consist of wavelenght from 250 to $2500 \mathrm{~nm}$ (Fig. 1) with spectral distribution maximum in visible light regime.

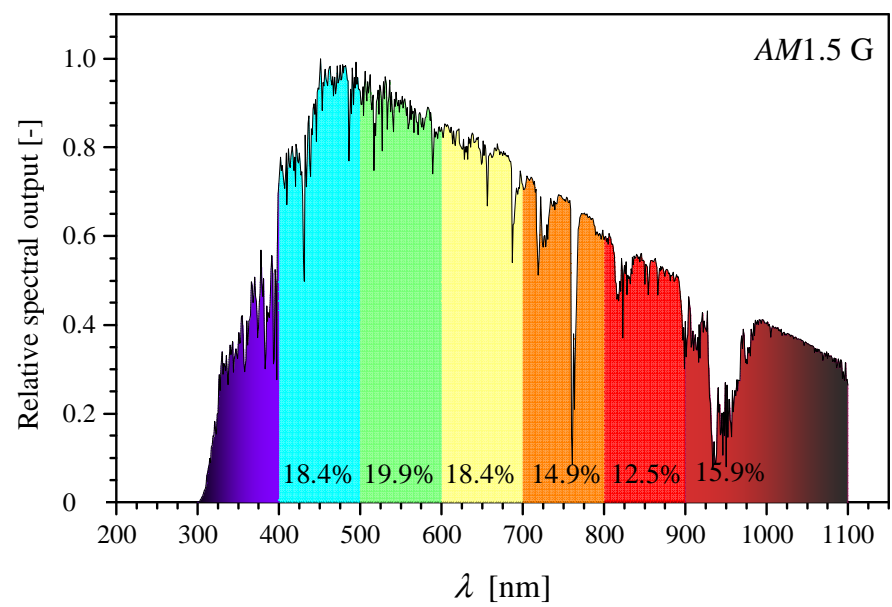

Fig. 1. Reference solar relative spectral irradiance distribution at $A M 1.5$ attenuation [14]

The actual solar spectrum differs from a blackbody radiance at $5800 \mathrm{~K}$ because of absorption in the cool peripheral solar gas (Fig. 2) [15]. At ground level, the shape of the natural sunlight spectrum depends on different atmospheric parameters, such as water vapour, ozone, carbon dioxide, and clouds among others [13]. In order to simulate the radiation pass through atmosphere layers, the air mass, $A M$, coefficient has been determined. For the radiation incident angle $\theta\left[{ }^{\circ}\right]$, close to the normal to the Earth's surface, the $A M$ coefficient is given by:

$$
A M=\cos \theta^{-1}
$$

Above mentioned formula (eq. (2)) is accurate in narrow range of $\theta$, approximately up to $75^{\circ}$. To simulate the radiation path through thicker layers of atmosphere, Kasten and Young [16] proposed more complex equation for $A M$ coefficient calculation near the horizon:

$$
A M=\frac{1}{\cos \theta+0.50572(96.07995-\theta)^{-1.6364}}
$$




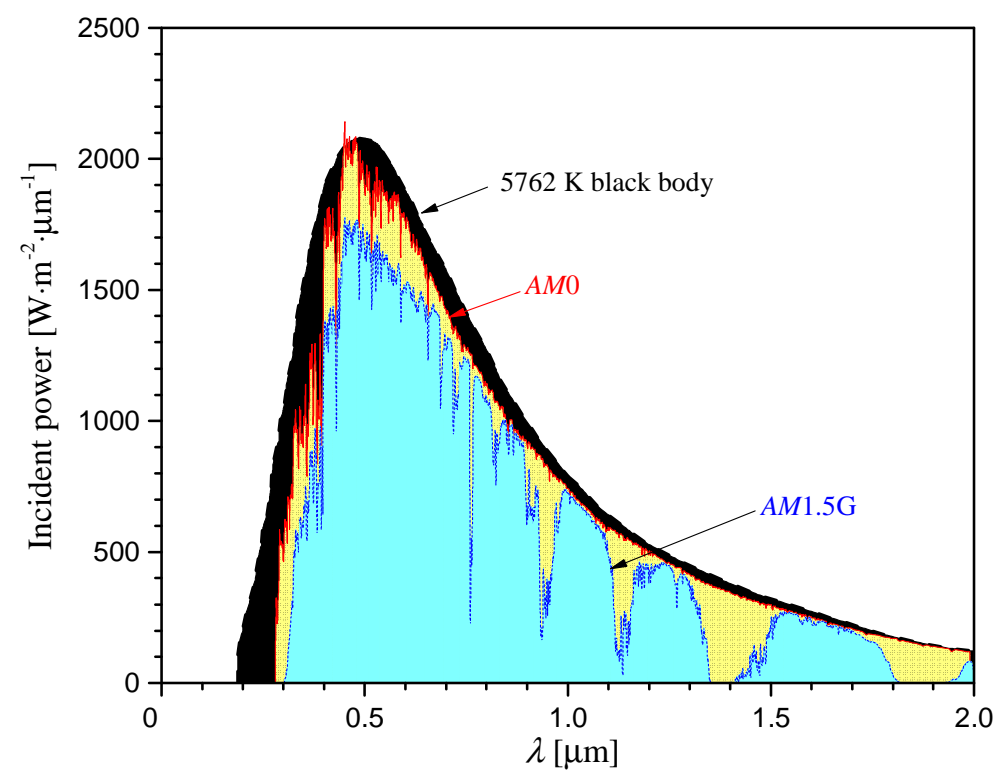

Fig. 2. Comparison between the radiation spectrum of black body at $5762 \mathrm{~K}, A M 0$ and AM1.5 (global) [15]

\section{Solar simulator versus artificial light source}

The application and design of solar radiation sources falls into two main classifications, non-concentrating, uniformly distributed solar simulators used mainly in the testing of photovoltaic (PV) cells and solar hot water collectors and high flux concentrators used to generate high temperatures exceeding $1000{ }^{\circ} \mathrm{C}$ [17].

The solar simulators used for simulation of daily normal irradiation (DNI) are classified in order to spectral distribution, beam uniformity and temporal stability (according to the IEC 60904-9, ASTM E927 \& JIS C8912 standards) [18]. The grades are awarded in presented order for each parameter, based on the deviation of offered parameters from standardized values. The best match is awarded with grade $A$, while the poorest is granted with grade $C$. The better the match, the higher the grade e.g. best match is granted with AAA, for simulators with worse beam uniformity ABA or ACA accordingly. Proper terrestrial solar simulators are designed to produce stable $1000 \mathrm{~W} \cdot \mathrm{m}^{-2}$ radiant flux, which is internationally standardized as 1 sun [19].

Solar devices used for studies that demand high temperatures at the target area and high radiant fluxes, are usually called light sources. The differentiation has been made due to omission of American Society for Testing and Materials (ASTM) standards, mainly because of intense radiation concentration, high output power, poor beam uniformity, and secondary approach to spectral match. The output power of artificial light sources, depending on design, can vary from 2 to 10000 suns [11]. In mentioned devices, the lamps are crucial factor influencing final device performance [14].

With that introduction it is clear that devices suitable for investigation of solar-thermal biomass conversion are high-power artificial light sources. Actually, solar simulators supported with proper radiation concentration device e.g. parabolic-through collector, 
parabolic dish or a set of mirrors could provide satisfactory radiant heat flux to carry out the reaction, however radiation concentration methods will be discussed in another paper.

\section{Light sources characterization}

Commercially available light sources consists of the lamp, being the heart of whole device, housing containing reflector, optics and cooling system, and finally the power supply [20]. The aim of this paper is comparative review of popular lamp types for high-powered light sources with secondary approach to the rest of the equipment.

In this study, the comparison of xenon, metal halide lamps and tungsten halogen will be presented. Each of mentioned lamps differs in terms of emissive spectrum, irradiance distribution, luminous efficiency and operational issues. Choice of final lamp type for declared research goal is crucial part of whole planning progress.

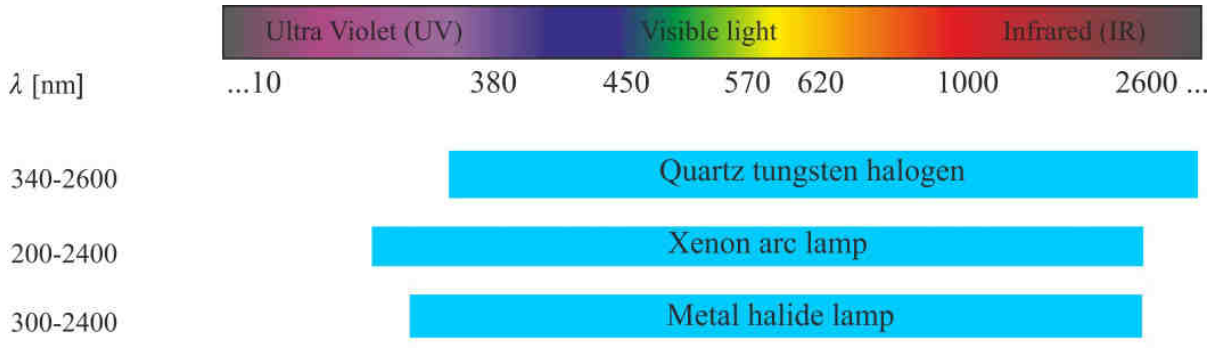

Fig. 3. Emissive spectrum range for three presented lamp types: quartz tungsten halogen, metal halide and xenon arc lamps

\section{Quartz tungsten halogen}

Quartz tungsten halogen is much cheaper than arc-type and efficient lamp, with spectral characteristics quite similar to natural sunlight [21]. Halogen lamps were widely popular in commercial use of the last decades e.g. for domestic and urban illumination or in the car industry. Nominal power of commercially available tungsten halogen lamps varies from 1, 10 to $1000 \mathrm{~W}$. Despite some of the spectral differences with natural sunlight, tungsten halogen found use in numerous solar thermal research applications [13]. Pozzobon et al. [22] presented study of experiments and modelling of wet wood decomposition. Proposed image furnace was powered by $750 \mathrm{~W}$ Tungsten halogen with two parabolic mirrors.

\section{Lamp construction}

A halogen lamp is a type of incandescent lamp, where a tungsten filament is surrounded by halogen gas in the form of bromine or iodine, heated with an electric current (Fig. 4) [14].

Burning of tungsten filament is simple and stable process, the lower the electric current, the lower the filament temperature and its emissive power. This fact provides major advantage of halogen-type lamps over arc lamps, being the simplicity of emissive power control in wide range, just with adjustment of the power supply. Simplicity of construction and low requirements for power supply, allow to easily arrange halogen lamps in multi-filament light sources to provide more output power. Kongtragool et al. [23] arranged 
4.1000 W tungsten halogen lamps to power gamma-configured Stirling engine. Total maximum solar input power has been estimated at $1378 \mathrm{~W}$, with heater temperature of $439 \mathrm{~K}$.

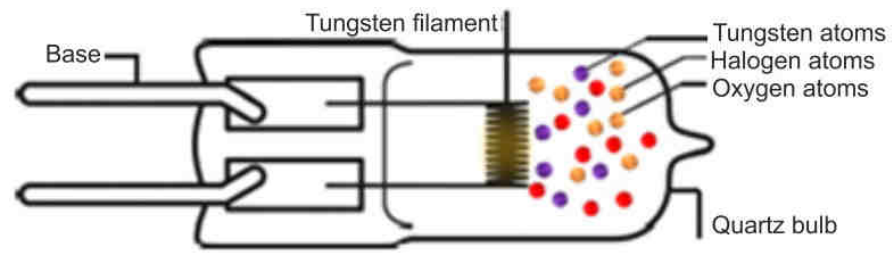

Fig. 4. Tungsten halogen lamp structure [13]

\section{Tungsten halogen emissive spectrum}

Tungsten halogen lamps provide smooth emissive power distribution with colour temperature of $3400 \mathrm{~K}$, with emissive maximum shifted towards infra-red (IR) regime, with lower ultra violet (UV) range [24]. Quartz tungsten halogen, presents smooth and stable spectrum in visible and near IR with very little UV regime. It can be said, that the lower the halogen nominal power, the shorter the UV emissive range.

\section{Xenon arc lamp}

Xenon arc lamps can be found in most of today's high-power light sources for biomass conversion research reactors, due to close matching natural sunlight with intensity and spectrum [25]. Boutin et al. [26] presented image furnaces for flash pyrolysis of biomass, powered by $5 \mathrm{~kW}$ xenon arc lamp with two parabolic mirrors. Gronli [27] investigated intermediate pyrolysis of single biomass pellet with direct sample heating by xenon arc lamp radiation. Lede [28] investigated ablative pyrolysis of biomass particles with xenon arc lamp, as a source of high-density heat flux in image furnace. With proper arrangements and concentration method, xenon lamps can easily produce incident heat fluxes as high as $10^{6}-10^{7} \mathrm{~W} \cdot \mathrm{m}^{-2}$ inside the focal point.

\section{Lamp construction}

Xenon arc lamp is typical example of discharge lamp. In presented lamp type, the source of radiation is the ionized xenon arc. Quartz bulb contains xenon gas under very high pressure, up to $4 \mathrm{MPa}$ (Fig. 5) [13]. Ignition of xenon arc demands very high direct current (DC) impulse (20 to $50 \mathrm{kV}$ ), with continuous care for stable power supply, in order to stabilize the arc and prevent any flicking or gleams. Once arc is formed, the lamp operates at lower voltages with higher electric current, reaching up to $50 \mathrm{~A}$, emitting bright light with significant amount of emitted heat, so the need of cooling occurs. Cooling is usually carried out by forced convection of air or with cooling liquid system. Xenon arc lamps are highly energy-consuming, and demand stable and smooth characteristic of the supplied power, what leads to conclusion, that almost $50 \%$ of total device cost stands for power supply only. Due to fragility of plasma arc, adjusting power supply parameters in order to regulate output power can vary between $70-100 \%$ in order to provide stable plasma arc. Further regulation must be done with regulation of the focal point position, external shutters or air-mass filters to cut out some of the power from emitted spectrum. 


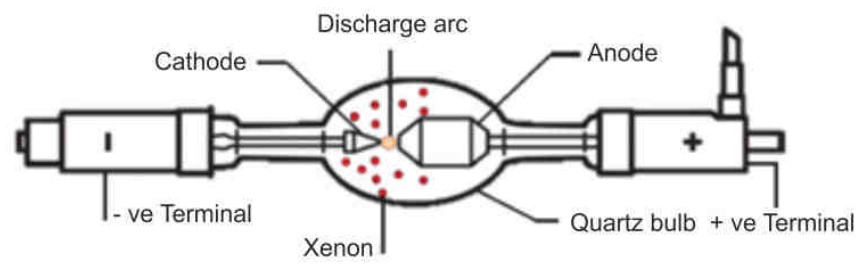

Fig. 5. Construction scheme of xenon arc lamp [13]

\section{Xenon arc lamp spectrum}

Xenon arc emits bright radiative flux (3000 cd for $1000 \mathrm{~W}$ lamp), that shows a good spectral fit with the natural sunlight, with colour temperature reaching $6200 \mathrm{~K}$ [21]. Presented lamps benefit from an excellent quality and stable spectrum in the UV and visible regimes. Their emission peaks in the IR range can be filtered if required [13].

\section{Metal halide lamp}

In a metal halide lamp, the light is produced by an electric arc which is generated through a gaseous mixture of vaporized mercury and metal halide compounds under a high pressure, ranging from 1 to $3.5 \mathrm{MPa}$ [13]. Metal halide lamps are commonly used in industrial illumination and they are still under development as light sources in high-powered light sources instead of xenon arc lights, whose tend to have high power consumption and high electronic driver costs [21]. Presented lamps has been a subject of numerous studies on solar simulators for photovoltaic studies, yet hardly powered any reactor for biomass conversion.

\section{Lamp construction}

The construction of metal halide lamp is somehow similar to halogen and xenon arc lamp as well. The idea is based on arc-lamp enclosed in outer bulb, mounted in one socket with two electrodes. Metal halide lamps (Fig. 6) are perceived as efficient radiation source with long lifetime and low-risk exploitation.

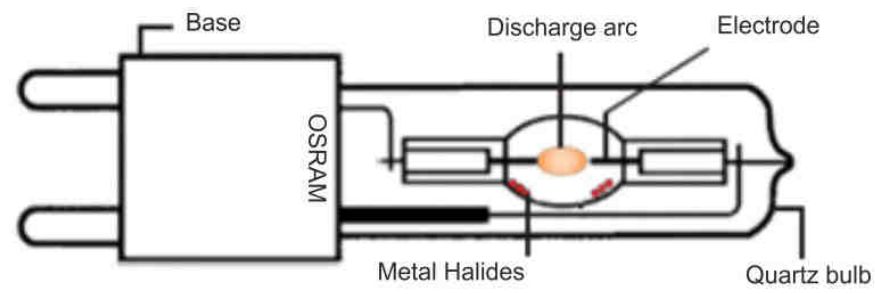

Fig. 6. Construction scheme of metal halide lamp [13] 


\section{Metal halide lamps spectrum}

The metal halide lamp is an artificial light source that emits a radiation spectrum that closely mimics that of natural sunlight. Metal halide emissive spectrum yields very close matching with natural sunlight in UV and near visible light regions, with colour temperature varying from 4000-6000 K, depending on the lamp construction [13]. The intense infrared energy spikes that xenon lamps emit require either forced air cooling for low wattage lamps or water cooling for higher powered lamps [17].

\section{Technical data}

Table 1 lists technical parameters of presented lamp types. From operator's point of view, the crucial parameters are average life time of the burner, internal pressure, as the safety issue, colour temperature and finally conversion efficiency. Tawfik et al. [13] presented a comprehensive review of lamp types for solar-thermal applications. In his work conversion efficiency was expressed as a percentage ratio between radiant output power and nominal electrical power of the lamp.

Comparison of technical parameters for the tungsten halogen, metal halide and xenon arc lamps [13]

\begin{tabular}{|c|c|c|c|}
\hline Criteria & Tungsten halogen & Metal halide & Xenon arc \\
\hline Average life time [hours] & $35-480$ & $1000-6100$ & $400-3500$ \\
\hline Internal pressure [MPa] & $0.7-1$ & $1-3.5$ & $1-4$ \\
\hline Colour temperature [K] & $2100-3350$ & $4000-6000$ & 6000 \\
\hline Average conversion efficiency [\%] & 10.21 & 24.59 & 18.77 \\
\hline
\end{tabular}

Table 2 lists some of the recently developed solar pyrolytic reactors, based on artificial light sources. Undeniably the most popular lamp type chosen by researchers is xenon arc lamp, with no denoted studies using metal halide lamps so far. Both tungsten halogen and xenon arc lamps provide good thermal performance for the biomass conversion process. In case of pyrolysis, presented artificial solar reactors proved reaching wide range of temperatures and heating rates covering slow, intermediate and flash pyrolysis technology requirements [29]. Incident heat fluxes listed in Table 2 are the product of lamp radiant power and radiation concentration method. The highest incident heat fluxes has been denoted for using elliptical mirrors and reflectors concentrating radiation on a single focal point $[30,31]$.

Table 2 Summary of the recently developed solar pyrolysis reactors based on artificial light sources with emphasis on the operating parameters

\begin{tabular}{|c|c|c|c|c|c|}
\hline Lamp type & $\begin{array}{c}\text { Nominal } \\
\text { power }[W]\end{array}$ & $\begin{array}{c}\begin{array}{c}\text { Concentration } \\
\text { method }\end{array} \\
\end{array}$ & $\begin{array}{c}\text { Incident heat flux } \\
{\left[\mathrm{W} \cdot \mathrm{m}^{-2}\right] \cdot \mathbf{1 0}^{3}}\end{array}$ & $\begin{array}{c}\text { Process } \\
\text { temperature }\left[{ }^{\circ} \mathrm{C}\right]\end{array}$ & References \\
\hline Xenon arc lamp & 5000 & Two elliptical mirrors & $1000-7400$ & $800-1000$ & [30] \\
\hline Xenon arc lamp & 5000 & Parabolic dish & $200-700$ & $750-900$ & [29] \\
\hline Xenon arc lamp & - & Lamp reflector & $80-130$ & $300-550$ & [27] \\
\hline Xenon arc lamp & 5000 & Parabolic dish & $200-900$ & $550-850$ & [25] \\
\hline Tungsten lamp & 750 & Two elliptical mirrors & $60-180$ & $700-800$ & [22] \\
\hline Xenon arc lamp & 1000 & Elliptical reflector & 2200 & $700-900$ & [31] \\
\hline
\end{tabular}




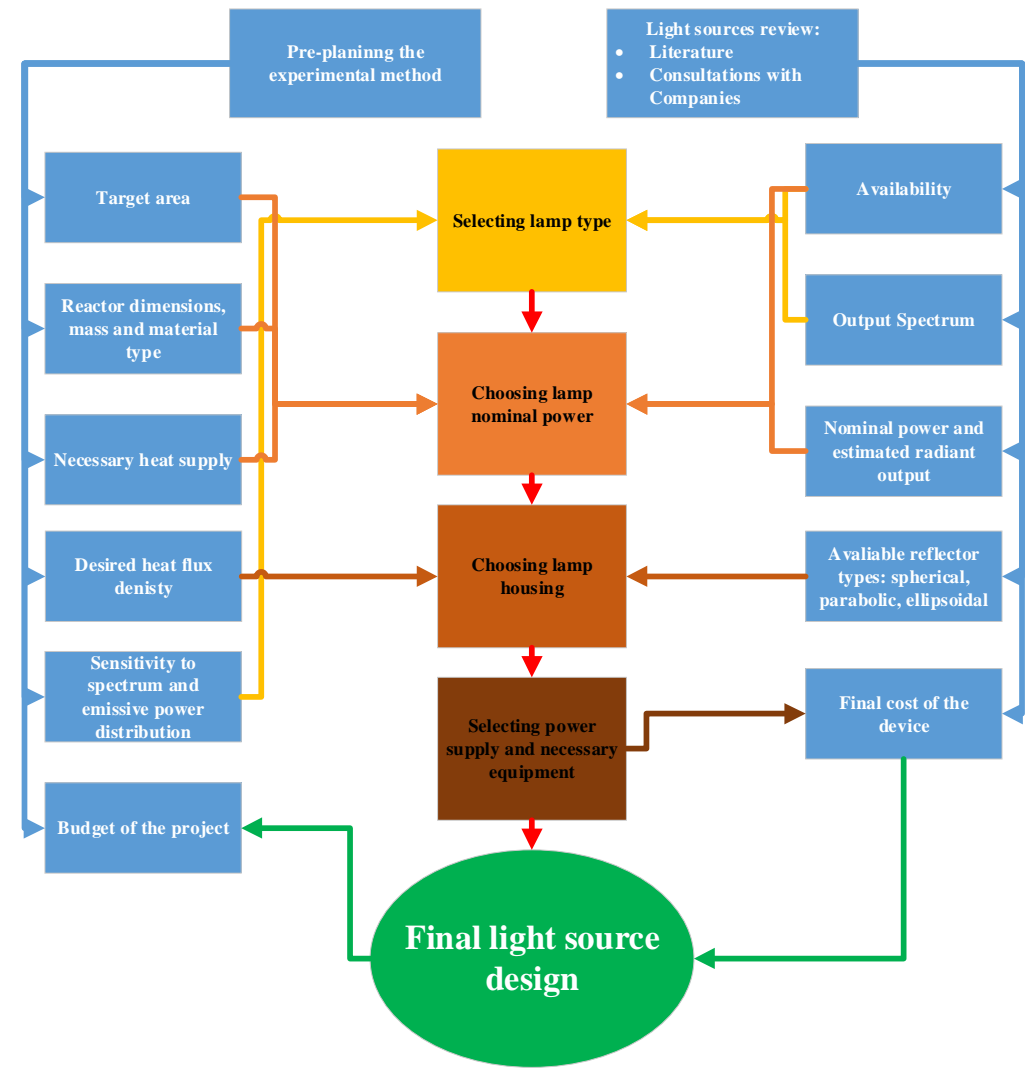

Fig. 7. Course of decisions taken during the selection light source for the study of solar pyrolysis of waste biomass

Figure 7 presents course of decision taken during choice of artificial light source for solar pyrolysis study. First, target area was specified with emphasis on high heat flux density at single focal point. Second, due to simulation of solar radiation, lamp emissive spectrum was taken into account. When crude lamp specification was established, numerous companies were contacted in order to discern the market and check lamps availability. For our study the best option was xenon arc light source with elliptical reflector focusing radiation at focal point with irradiated area of a circle with $1 / 2$ " diameter. $1.6 \mathrm{~kW}$ nominal power with average conversion efficiency (Table 1) should provide $2.2 \mathrm{MW} \cdot \mathrm{m}^{-2}$ heat flux density, what regarding literature, should provide plenty of heat for small solar pyrolysis reactor. Results of solar pyrolysis experiments with selected light source are already presented elsewhere [31].

\section{Conclusions}

In presented paper, the review of artificial light sources for solar-thermal biomass conversion research applications. Authors of this paper faced the challenge of artificial light source choice, in order to design research stand for examination of solar pyrolysis 
phenomena. Into considerations were taken: spectral characteristics, radiant output power, availability and final cost. Virtually each type of presented lamp can provide high output power arranged into high-density heat flux. Presented examples shows, that artificial light based biomass conversion reactors are able to investigate solar pyrolysis, torrefaction or even gasification. Halogen type lamps are the best option for studies with secondary approach to radiation spectrum but with emphasis on stable output power regulation. Halogen lamps does not require sophisticated power supply, and can be easily arranged into multi-source devices with very high output power. Xenon arc and metal halides lamps due to operation of ionized arcs emits radiation with good spectral match regarding to natural sunlight. High output power requires dedicated power supply, what generates cost of final device. Due to lack of metal halide light sources commercially available, the choice had to make between tungsten halogen and xenon arc lamps. The urgent need of good spectral match with natural sunlight caused, that the xenon arc lamp sort out to be superior. Regarding metal halides, they are very promising lamps for future studies, based on their very long life time and the fact that some of them can put higher intensities of UV. Still, due to the lack of commercially available solutions based on metal halides, the xenon arc lamps seems to be the best option for simulation of high-power solar radiation. After consultancies with numerous companies, authors gained knowledge regarding to artificial light sources operational, safety, thermal and optical issues. In order to construct solar pyrolysis reactor, the decision fell on $1.6 \mathrm{~kW}$ xenon arc based, complete light source with ellipsoidal reflector, providing high density heat flux, up to $2.2 \mathrm{MJ} / \mathrm{m}^{2}$ at the target area. The performance of the light source and designed reactor with solar pyrolysis study results will be discussed and presented in the future papers.

\section{Acknowledgements}

This paper has been prepared within the frame of the project "Study on the solar pyrolysis process of the Waste biomass", financed by the National Science Centre, Poland (registration number 2016/23/B/ST8/02101).

\section{References}

[1] Adib R, Folkecenter M, Eckhart M, El-Ashry M, Hales D, Hamilton K, et.al. Renewables 2018. Global Status Report. Paris: REN21; 2018. ISBN 9783981891133.

[2] Chew JJ, Doshi V. Recent advances in biomass pretreatment - Torrefaction fundamentals and technology. Renew Sustain Energy Rev. 2015:15:4212-4222. DOI: 10.1016/j.rser.2011.09.017.

[3] Basu P. Biomass Gasification and Pyrolysis Handbook. Academic Press, Elsevier; 2010. ISBN 9780123749888.

[4] Prins MJ, Ptasinski KJ, Janssen FJJG. More efficient biomass gasification via torrefaction. Energy. 2006:31:3458-3470. DOI: 10.1016/j.energy.2006.03.008.

[5] Werle S, Wilk RK. A review of methods for the thermal utilization of sewage sludge: The Polish perspective. Renew Energy. 2010:35:1914-1919. DOI: 10.1016/j.renene.2010.01.019.

[6] Zeng K, Gauthier D, Minh DP, Weiss-Hortala E, Nzihou A, Flamant G. Characterization of solar fuels obtained from beech wood solar pyrolysis. Fuel. 2017:188:285-293. DOI: 10.1016/j.fuel.2016.10.036.

[7] Čepeliołullar Ö, Pütün AE. Products characterization study of a slow pyrolysis of biomass-plastic mixtures in a fixed-bed reactor. J Anal Appl Pyrolysis. 2014:110:363-374. DOI: 10.1016/j.jaap.2014.10.002.

[8] Mangut V, Sabio E, Gañán J, González JF, Ramiro A, González CM et al. Thermogravimetric study of the pyrolysis of biomass residues from tomato processing industry. Fuel Process Technol. 2006;87:109-115. DOI: 10.1016/j.fuproc.2005.08.006.

[9] Wang S, Dai G, Yang H, Luo Z. Lignocellulosic biomass pyrolysis mechanism: A state-of-the-art review. Prog Energy Combust Sci. 2017:62:33-86. DOI: 10.1016/j.pecs.2017.05.004. 
[10] Zeng K, Gauthier D, Soria J, Mazza G, Flamant G. Solar pyrolysis of carbonaceous feedstocks: A review. Solar Energy. 2017:156:73-92. DOI: 10.1016/j.solener.2017.05.033.

[11] Isemin R, Mikhalev A, Klimov D, Grammelis P, Margaritis N, Kourkoumpas DS et al. Torrefaction and combustion of pellets made of a mixture of coal sludge and straw. Fuel. 2017:210:859-865. DOI: 10.1016/j.fuel.2017.09.032.

[12] Smets A, Jager K, Isabella O, Swaai RV, Zeman M. Solar Energy: The Physics and Engineering of Photovoltaic Conversion Technologies and Systems. Cambridge, England: UIT; 2016. ISBN 9781609860325.

[13] Tawfik M, Tonnellier X, Sansom C. Light source selection for a solar simulator for thermal applications: A review. Renew Sustain Energy Rev. 2018:90:802-813. DOI: 10.1016/j.rser.2018.03.059.

[14] Grandi G, Ienina A, Bardhi M. Effective low-cost hybrid LED-halogen solar simulator. IEEE Trans Ind Appl. 2014;50:3055-3064. DOI: 10.1109/TIA.2014.2330003.

[15] Luque A, Hegedus S, editors. Handbook of Photovoltaic Science and Engineering. Wiley; 2011. DOI: 10.1002/9780470974704. ISBN 9780470721698.

[16] Kasten F, Young AT. Revised optical air mass tables and approximation formula. Appl Optics. 1989;28:4735-4738. DOI: 10.1364/AO.28.004735.

[17] Ekman BM, Brooks G, Rhamdhani MA. Development of high flux solar simulators for solar thermal research. Energy Technol. 2016;141:149-159. DOI: 10.1007/978-3-319-48220-0_17.

[18] Chawla MK. A step by step guide to selecting the "right" solar simulator for your solar cell testing application. Photo Emission Tech Inc. 2017:1-6.

[19] Georgescu A, Damache G, Gîrţu MA. Class A small area solar simulator for dye-sensitized solar cell testing. J Optoelectron Adv Mater. 2008;10:3003-3007.

[20] Sciencetech Inc. Light Sources Overview. http://www.sciencetech-inc.com/all-products/light-sources/lightsources.html, 2018.

[21] Esen V, Sağlam Ş, Oral B. Light sources of solar simulators for photovoltaic devices: A review. Renew Sustain Energy Rev. 2017;77:1240-1250. DOI: 10.1016/j.rser.2017.03.062.

[22] Pozzobon V, Salvador S, Bézian JJ, El-Hafi M, Le Maoult Y, Flamant G. Radiative pyrolysis of wet wood under intermediate heat flux: Experiments and modelling. Fuel Process Technol. 2014;128:319-330. DOI: 10.1016/j.fuproc.2014.07.007.

[23] Kongtragool B, Wongwises S. A four power-piston low-temperature differential Stirling engine using simulated solar energy as a heat source. Solar Energy. 2008;82:493-500. DOI: 10.1016/j.solener.2007.12.005.

[24] Boulet P, Parent G, Acem Z, Collin A, Försth M, Bal N, et al. Radiation emission from a heating coil or a halogen lamp on a semitransparent sample. Int $\mathbf{J}$ Therm Sci. 2014;77:223-232. DOI: 10.1016/j.ijthermalsci.2013.11.006.

[25] Authier O, Lédé J. The image furnace for studying thermal reactions involving solids. Application to wood pyrolysis and gasification, and vapours catalytic cracking. Fuel. 2013;107:555-569. DOI: 10.1016/j.fuel.2013.01.041.

[26] Boutin O, Ferrer M, Lédé J. Radiant flash pyrolysis of cellulose - Evidence for the formation of short life time intermediate liquid species. J Anal Appl Pyrolysis. 1998;47:13-31. DOI: 10.1016/S0165-2370(98)00088-6.

[27] Grønli M, Melaaen MC. Mathematical model for wood pyrolysis - Comparison of experimental measurements with model predictions. Energy Fuels. 2000;14:791-800. DOI: 10.1021/ef990176q.

[28] Lédé J. Comparison of contact and radiant ablative pyrolysis of biomass. J Anal Appl Pyrolysis. 2003;70:601-618. DOI: 10.1016/S0165-2370(03)00043-3.

[29] Rony AH, Mosiman D, Sun Z, Qin D, Zheng Y, Boman JH et al. A novel solar powered biomass pyrolysis reactor for producing fuels and chemicals. J Anal Appl Pyrolysis. 2018;132:19-32. DOI: 10.1016/j.jaap.2018.03.020.

[30] Boutin O, Ferrer M, Lédé J. Flash pyrolysis of cellulose pellets submitted to a concentrated radiation: Experiments and modelling. Chem Eng Sci. 2002;57:15-25. DOI: 10.1016/S0009-2509(01)00360-8.

[31] Sobek S, Werle S. Solar pyrolysis of waste biomass: Part 1 reactor design. Renew Energy. 2019;143:1939-1948. DOI: 10.1016/j.renene.2019.06.011. 